\title{
Calculating and interpreting multipliers in the presence of non-Stationary time series: The case of U.S. federal infrastructure spending
}

\author{
Lonnie K. Stevans and David N. Sessions \\ Frank G. Zarb School of Business, Department of IT/QM \\ Hofstra University Hempstead, NY 11549
}

\begin{abstract}
In this analysis, we discuss two measures that have been used by economists to measure longrun changes in macroeconomic policies: the dynamic multiplier and the impulse response function. In the presence of $I(1)$ variables, if the multipliers/impulse responses are generated from a VAR model, there can be substantial biases at both the long and short-run horizons. In this paper, the influence that infrastructure spending will have on U.S. economy from 2009 to 2010 is examined by modeling selected macroeconomic variables as a Vector Error Correction (VEC) model. The impulse response function will then be used to generate government spending multipliers and bootstrapped confidence intervals. Findings indicate a Federal infrastructure spending multiplier of 3.33 at the end of a two year period.
\end{abstract}

Keywords: dynamic multiplier, impulse response function, Vector Error Correction (VEC), Vector Autoregressive (VAR)

JEL Codes: E62, H54, C32

\section{INTRODUCTION}

The current focus on economic stimulus and infrastructure spending raises questions regarding the magnitude of the effect, both in the short and long-run, of government purchases on other macroeconomic variables such as consumption, net investment, prices, unemployment and real GDP?

The empirical techniques used by economists in discussions regarding the response of the economy to actions taken by the monetary and fiscal authorities have changed over time. For example, the dynamic multiplier was popular until the 1980s. Calculation of the dynamic multiplier usually involved one of two competing methodologies: (1) Keynesians used structural macroeconometric models which were versions of the IS-LM model in which policy variables were "shocked" in order to compute dynamic multipliers, and; (2) Monetarists estimated single reduced form equations of the change in GNP to lagged changes in monetary and fiscal policy variables--interpreting the coefficients' sums of the lagged policy variables as dynamic multipliers. A novel method of calculating multipliers was developed during the 1980s using Vector Autoregressive models (VAR) and impulse response functions. Unlike standard macroeconomic structural models, the use of VAR assumes that all variables are endogenous. The exogenous "variables" are the innovations or error terms of the VAR system.

The purpose of this study is not to contribute further to the Keynesian-Monetarist debate. We begin with a brief discussion of the ways multipliers have been calculated in the literature. While impulse response analysis is the most widespread technique used to uncover the dynamic relationship between macroeconomic variables within VAR models, the nature of these relationships can be misleading both in the short and long-run if the variables are nonstationary (Mitchell (2000)) and thus the notion of multipliers would have to be reassessed in the context of time series that exhibit hysteresis. In this analysis, we shall examine the properties of calculating multipliers in the presence of nonstationary variables. Moreover, the influence that Federal spending will have on the U.S. economy over the next four years, (2009-2012), will be appraised by modeling selected macroeconomic variables as a Vector Error Correction (VEC) model and then using the impulse response function to generate the government spending multipliers and bootstrapped confidence intervals. While many studies in the literature have calculated multipliers, none have done so using non-stationary economic time series and VEC models. 


\section{MACROECONOMIC STRUCTURAL MODELS}

Following the approach taken by the Cowles Commission, in the 1960s and 1970s, Keynesians used a technique known as "comparative dynamic simulation" to analyze the impact of a macroeconomic policy action (Klein and Young (1980); Modigliani (1971)). Macroeconomic variables are classified as either endogenous, exogenous, or pre-determined. The endogenous variables are then determined as the solution of a set of simultaneous equations conditional on the values of fixed model coefficients, exogenous, and pre-determined variables. The exogenous variables are variables whose values are determined outside the model and the pre-determined variables are lagged endogenous variables. All variables are assumed to be stationary $(I(0))$. This can all be written in the form of an equation system with $k$ structural equations, a $k \times 1$ vector of endogenous variables $\stackrel{\mathrm{v}}{Y}_{t}$, a $g \times 1$ vector of

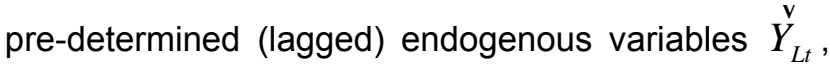
and a $w \times 1$ vector of exogenous variables $\stackrel{\mathrm{v}}{X}_{t}$,

$\Theta \stackrel{\mathrm{v}}{Y}_{t}=\Phi{\stackrel{\mathrm{v}}{Y_{L t}}}+\Omega \stackrel{\mathrm{v}}{X}_{t}+{\stackrel{\mathrm{v}}{\varepsilon_{t}}}_{\text {. }}$

$\Theta$ is a nonsingular matrix of coefficients of current period endogenous variables, $\Phi$ is a matrix of coefficients of pre-determined variables, $\Omega$ is a matrix of coefficients of exogenous variables (including the intercept), and $\varepsilon_{t}$ is a disturbance vector. The reduced form may be written by multiplying each side of equation (1) by $\Theta^{-1}$,

$\stackrel{\mathrm{v}}{Y}_{t}=\Theta^{-1} \Phi Y_{L t}^{\mathrm{v}}+\Theta^{-1} \Omega \mathbb{X}_{t}+\Theta^{-1} \dot{\varepsilon}_{t}$

$\stackrel{\mathrm{V}}{Y_{t}}=\Lambda_{1} \stackrel{\mathrm{V}}{L t}_{\mathrm{V}}+\Lambda_{2} \mathrm{X}_{t}^{\mathrm{V}}+\eta_{t}$

where $\Lambda_{1}$ and $\Lambda_{2}$ are the matrices of reduced form coefficients. For models that have only first-order lags, the equation of the reduced form of the system can be written as,

$\dot{v}_{t}=\Xi Y_{t-1}^{\mathbf{v}}+\Lambda_{2} \stackrel{v}{X}_{t}+\eta_{t}$.

$\Xi$ is a "companion" matrix formed from the columns of $\Lambda_{1}$ including columns of zeros, arranged in the order in which the variables meet the lags. The elements of $\Lambda_{2}$ are called impact multipliers because they represent the immediate effect of changes in each exogenous variable on the values of the endogenous variables. Equation (3) may be rewritten as,
$\stackrel{\mathbf{v}}{Y_{t}}=\Xi^{2} \stackrel{\mathrm{v}}{Y}_{t-2}+\Xi \Lambda_{2} \stackrel{\mathrm{v}}{X}_{t-1}+\Lambda_{2} \stackrel{\mathrm{v}}{X}_{t}+{\stackrel{\mathrm{v}}{\gamma_{t}}}_{\text {. }}$

The matrix formed by the product $\Xi \Lambda_{2}$ is the effect of the exogenous variables one lag in the past. The elements in this matrix are called interim multipliers. The ith period interim multipliers are formed by $\Xi^{i} \Lambda_{2}$

Stationarity conditions require that the eigenvalues of the companion matrix are less than the unit circle value and that $(I-\Xi)^{-1}$ exist. Therefore, the particular or "long-run" solution to equation (3) can be written as,

$\Psi_{L R}=(I-\Xi)^{-1} \Lambda_{2} \stackrel{\mathrm{v}}{X}_{L R}$,

and the elements of $(I-\Xi)^{-1} \Lambda_{2}$ are known as

dynamic multipliers.

Evidence that macroeconometric models are still being used can be seen by visiting the Fair Model and Macroeconomic Advisors websites. iii In addition, private consultants and the Fed still use the largescale models for policy evaluation and forecasting.

\section{REDUCED FORM SINGLE EQUATION MODELS}

Monetarists argued that no structural model, however, large and detailed, could present a realistic view of how money effected economic growth. They estimated single equation reduced form models in which a measure of nominal economic activity was regressed on nominal values of exogenous policy variables and interpreted the coefficients of the reduced form equation as policy multipliers, ceteris paribus.

Anderson and Jordan (1968) presented a reduced form model that became known as the St. Louis Equation (from the Federal Reserve Bank of St. Louis). The specification was an equation in first differences,

$\Delta Y_{t}=\sum_{i=1}^{p} \beta_{i} \Delta X_{1 t-i}+\sum_{i=1}^{p} \gamma_{i} \Delta X_{2 t-i}+\ldots .+\sum_{i=1}^{p} v_{i} \Delta X_{w t-i}+\varepsilon_{t}$,

where nothing but the $w$ policy variables appeared on the right-hand-side. Tests of the long-run effectiveness of the policy instruments were performed by testing the statistical significance of the sums of the estimated distributed lag coefficients, $\sum_{i=1}^{p} \hat{\beta}_{i}, \sum_{i=1}^{p} \hat{\gamma}_{i}, \ldots, \sum_{i=1}^{p} \hat{v}_{i}$. As will be seen shortly, an 
equation using first differences is miss-specified if the variables are cointegrated.

An important issue in the empirical debate between Monetarists and Keynesians was the magnitude of the government spending multiplier. Keynesians believed that the fiscal multipliers were large while Monetarists believed that they were zero due to the crowding-out of private investment spending. Each had their position corroborated by the technique used. Dynamic simulations from large-scale Keynesian macroeconometric models exhibited large fiscal effects while the fiscal multipliers obtained from the Monetarist St. Louis equation were not significantly different from zero. For many years, Keynesians and Monetarists attacked the validity of each other's multiplier estimation techniques citing the problem topics of omitted variable bias, reverse causality, and exogeneity (Fisher (1988)).

\section{VECTOR AUTOREGRESSIVE MODELS (VAR)}

Sims (1980) developed a new reduced form multivariate methodology known as Vector Autoregressive Models (VAR). One of the uses of VAR that most closely resembles the dynamic multiplier is the impulse response function. He estimated a VAR model in which the endogenous variables were $\mathrm{M} 1$, real GNP, the unemployment rate, the wage rate, the GNP deflator, and import prices.

In the simplest form of a VAR model, a set of observable variables is chosen, a maximum lag length is chosen, and the current value of each variable is regressed on the lagged values of that variable and all other variables. No exogenous variables exist since all observable variables are treated as endogenous. In this manner, a VAR is very similar to the unrestricted reduced form addressed above (equation (2)). Recalling that all variables are considered endogenous $\left(\stackrel{v}{W}_{t}^{\prime}=\left(Y_{t}^{v}, \stackrel{v}{X}_{t}\right)^{\prime}\right)$, the VAR can be written as, ${ }^{\vee}$

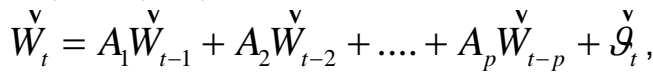

where $E\left(\grave{\vartheta}_{t}\right)=0$ and $\grave{\vartheta}_{t}$ has time invariant variancecovariance matrix $E\left(\vartheta_{t} \vartheta_{t}^{\prime}\right)=\Sigma_{\vartheta}$. Since $\stackrel{v}{W}$ is stationary, $(I(0))$, it has a Wold infinite moving average representation,

$$
\begin{aligned}
& \mathrm{W}_{t}=\tau^{-1} \stackrel{\mathrm{V}}{t}_{t}=\sum_{i=0}^{\infty} \underline{\varphi}_{i} \mathrm{~V}_{t-i}^{\mathrm{V}} \\
& \left(I-\sum_{v=1}^{p} \mathrm{~A}_{v}\right)=\tau \\
& \varphi_{i}=\left(\sum_{v=1}^{p} \mathrm{~A}_{v}\right)^{i}=\left(\begin{array}{ccc}
\varphi_{11} & \mathrm{~K} & \varphi_{1 d} \\
\mathrm{M} & \mathrm{O} & \mathrm{M} \\
\varphi_{d 1} & \mathrm{~L} & \varphi_{d d}
\end{array}\right)^{i}
\end{aligned}
$$

The coefficients $\varphi_{j c}^{i}(j, c=1,2,3, \ldots ., d)$ represent the impact of a change in the innovations, $\vartheta_{t}^{v}$, on the endogenous variables and are known as the impulse response function of $W_{t}$. For $i=1,2,3, \ldots$, the $\varphi_{j c}^{i}$ may be interpreted as interim multipliers. The sum of the interim multipliers, $\sum_{i=0}^{l} \varphi_{j c}^{i}$, is the total multiplier after $l$ periods.

Since the innovations $\vartheta_{t}^{v}$ across equations are correlated, the components of the impulse responses $\varphi_{j c}^{i}$ in equation (8) are difficult to construe. In order to aid in interpretation, many econometric software packages make use of the Cholesky decomposition which transforms the innovations so that they are orthogonal to each other. ${ }^{\mathrm{vi}}$ The innovations are also usually standardized to have a variance/standard deviation equal to one.

There needs to be some clarification regarding the equivalence of multipliers using the macroeconometric models (3), (4), (5), on one hand, and the reduced form of the VAR model in equation (7), on the other. Stein and Song (2002) have shown that the impact, interim, and dynamic multipliers computed from equation (3), (4), and (5) are equivalent to the multipliers evaluated from the VAR impulse response weights (above) only when the imposed restrictions of weak exogeneity, no serial correlation, and independence of the error terms are imposed on the VAR. Thus, under these restrictions, as $l$ approaches infinity, the sum converges to the dynamic multiplier (equation (5)),

$$
\lim _{l \rightarrow \infty} \sum_{i=0}^{l} \varphi_{j c}^{i}=\Psi_{L R} .
$$


Of course, Stein and Song (2002) did not consider was the fact that the limit (9) exists if and only if the endogenous variables in $W_{t}$ are stationary. If any of these restrictions are not imposed nor binding, then the limit of the total multiplier in (9) converges, but not to the same dynamic multiplier that would result from a reduced form, macroeconometric model (equation (5)) and the sums of the coefficients of lagged policy variables are interpreted as the total multiplier in VAR models (this was done in the single St. Louis Equation). The problem with using these sums rather than the impulse responses is that there is no way of controlling for the interaction of shocks within a system.

VAR models and their associated impulse response functions have been used to determine whether government spending stimulates other spending in the economy. Blanchard and Perotti (2002) estimate fiscal "shocks" using VAR models. Institutional information on taxes, transfers, and spending are incorporated to set parameters then the VAR is estimated. They find that government spending does not respond to GDP or taxes contemporaneously and that consumption rises in response to a positive government spending shock. Alternatively, Ramey (2008) has explored possible explanations for the dramatically different results between standard VAR methods and the narrative approach for identifying shocks to government spending. She finds that consumption and other categories stay about the same when the government spends more--the increase in GDP is about equal to the increase in government spending. To focus on changes in government spending that are not themselves responding to conditions in the economy, she considers military spending and finds that GDP rises by about the same amount as an increase in military spending. However, the problem with both of these approaches is that neither tests for cointegrating relationships and therefore run the risk of missspecification in estimation as well as in the computation of the impulse response function.

\section{VECTOR ERROR CORRECTION MODELS (VEC)}

When the VAR is specified in first differences, as is expressed in Andersen and Jordan (1968), Sims (1980), and Stein and Song (2002) an implicit assumption is that all variables are $I(1)$ and there is no cointegration. However, if there is cointegration, then estimation of a VAR specified in first differences is subject to misspecification error since the error correction term, $\pi Y_{t-1}$, is omitted,

$$
\begin{aligned}
& \Delta \mathrm{V}_{t}=\pi \mathrm{V}_{t-1}+\sum_{i=1}^{p-1} \pi_{i} \Delta \stackrel{\mathrm{V}}{t-1}+\stackrel{\mathrm{V}}{\vartheta_{t}}, \\
& \pi=-\left(I-\sum_{i=1}^{p} A_{i}\right)=\alpha \beta^{\prime} \\
& \pi_{i}=-\sum_{j=i+1}^{p} A_{j} .
\end{aligned}
$$

The dimension of both $\alpha$ and $\beta$ is $k \times r$, where $r$ is the cointegrating rank (or the rank of $\pi$ ). Moreover, according to Mitchell (2000), when cointegration is present but not imposed in estimation, there can be substantial biases at the short horizon as well as the long. His results suggest that, in contrast to common practice, before conducting impulse response analysis, researchers should analyze the cointegrating properties of the data and appropriately restrict the VAR (e.g., estimate a reduced rank VAR) when the data are cointegrated. In order to get the impulse response functions from the VEC, equation (9) is estimated and these estimates are used to transform the VEC into an equivalent VAR.

The problem here lies in the fact that in the presence of non-stationary variables, the long-run dynamic multiplier is undefined, e.g., $\lim _{l \rightarrow \infty} \sum_{i=0}^{l} \varphi_{j c}^{i}=\infty$ and consequently there is no Wold representation as specified in equation (8). In contrast to the stationary case, some of the shocks "hitting" a non-stationary system may have permanent, long-run effects and the dynamic or long-run multiplier does not exist for changes in innovations that have permanent effects, since the multiplier in (9) above would increase without bound. However, impact, interim and accumulated or total multipliers can still be calculated, along with their associated statistical properties.

\section{STATISTICAL PROPERTIES OF MULTIPLIERS}

One way of representing the statistical properties of the multiplier is by asymptotic distribution results. According to Vlaar (2004), if the reduced form parameters are asymptotically Normal, the estimated impulse responses will also have an asymptotic Normal distribution since the impulse responses are a nonlinear function of the reduced form VEC parameters, 


$$
\begin{aligned}
& \hat{\varphi}=\hat{\varphi}(\hat{\gamma}) \\
& \hat{\gamma}^{\prime}=\left(\hat{\pi}_{1}, \hat{\pi}_{2}, \ldots, \hat{\pi}_{p-1}, \hat{\pi}\right), \\
& \sqrt{T}(\hat{\varphi}-\varphi) \rightarrow N\left(0, \Sigma_{\hat{\varphi}}\right)
\end{aligned}
$$

where $\Sigma_{\hat{\varphi}}$ is the variance-covariance matrix of the asymptotic distribution. ${ }^{\text {vii }}$ Since the accumulated multipliers are just a linear function of the impulse responses, they also have an asymptotic Normal distribution,

$$
\begin{aligned}
& \hat{m}_{l j c}=\sum_{i=1}^{l} \hat{\varphi}_{j c}^{i} \\
& \sqrt{T}\left(\hat{m}_{l j c}-m_{l j c}\right) \rightarrow N\left(0, \sigma_{\hat{m}_{l c}}^{2}\right)
\end{aligned}
$$

The variances $\sigma_{\hat{m}_{i j k}}^{2}$ are estimated by using the appropriate entries from $\Sigma_{\hat{\varphi}}$.

Asymptotic theory may not provide a good guide for small sample inference. Thus, bootstrap methods are often used to construct confidence intervals for impulse responses. These methods have the advantage of avoiding explicit forms of the complicated analytical expressions for $\Sigma_{\hat{\varphi}}$. Nonetheless, bootstrap methods generally do not overcome the problem of zero variances in the asymptotic distributions of the impulse responses and they may also provide confidence intervals which do not have the desired coverage level. ${ }^{\text {vii }}$

A key issue facing any political administration has to do with the size of fiscal policy multipliers. In their blog, Bob Hall and Susan Woodward look at spending increases from World War II and the Korean War and conclude that the government spending multiplier is about one-a dollar of government spending raises GDP by about a dollar. ${ }^{\text {ix }}$ Similarly, the results in Ramey (2008) suggest a government spending multiplier of about $1.4 .^{x}$ Barro argues that the government spending multiplier has never exceeded one, even during WWII. ${ }^{\mathrm{x}}$ How can these empirical differences be explained? As mentioned previously, Ramey (2008) uses impulse responses generated from a VAR, Hall and Woodward's results are more heuristic and graphical, and Barro's multipliers are calculated using simple averages and regression analyses similar to the St. Louis Model. Given all of these methods, it is our contention that in the face of nonstationary variables and possible cointegration, the VEC model with its resulting impulse response functions should be used to calculate multipliers.

\section{EMPIRICAL MODEL AND RESULTS}

According to Stein and Song (2002), the empirical debate between Monetarists and Keynesians during the 1950s, 1960s, and 1970s was more about dynamic multipliers than impulse response functions. Friedman (1972) classified policy events in terms of changes in variables, rather than what the policy does to the innovation. In other words, Monetarists were emphasizing dynamic multipliers and not impulse response functions. Our objective will be to use the impulse response functions generated from a VEC model (equation (10)) in order to calculate accumulated government spending multipliers at different periods and examine the future impact of Federal non-defense investment (infrastructure) spending on the following macroeconomic variables,

- Real M1 Money Supply,

- Nominal Long-Term Treasury Rate,

- Real Private Net Investment Spending,

- Real Private Consumption Spending,

- Real GDP,

- Price (GDP Implicit Price Chained Deflator),

- Real Personal Income Taxes, and

- the Unemployment Rate.

Federal non-defense investment spending was chosen because of its relevance to current policy. Given the nature of the problem and the challenging estimation issues involved in generating impulse response weights and their associated standard errors for VEC models, it was determined that the best software to use was JMulti 4.0. .iii $^{\text {xii }}$

All variables are in real terms except for the nominal long-term Treasury rate and the data is quarterly from 1960 to 2008. Federal non-defense investment is spending on public capital goods (and depreciation) by the Federal government. It has averaged approximately .762 percent of net domestic product since 1960.

In the 2009 \$789B stimulus package, the Federal government is planning to spend at least $\$ 100 \mathrm{~B}$ on infrastructure projects. ${ }^{\mathrm{xiv}}$ The following four questions have been raised in one context or another regarding the effect of government spending on the private U.S. economy,

- Will the rise in the deficit as a result of the stimulus be financed in such a way that will increase the money supply? 
- What will be the influence on private spending (both consumption and investment)?

- Because of the lag factor, will increasing government spending today generate inflation in the future?

- Will personal taxes have to rise in the future in order to pay for the increased spending in the present?

- Does increased government spending reduce unemployment?

- Finally, what is the ultimate effect on GDP? Will a stimulus deliver insofar as increasing overall economic activity in the U.S.?

These questions will be addressed in this study by generating and adding the impulse responses within the context of a VEC model in order to observe hypothetically what would happen to economic activity from 2009-2010 when the innovation of real Federal non-defense investment spending is increased by one standard deviation. A one standard deviation increase in real Federal non-defense investment spending is $\$ 9.48$ Billion.

A shock to the ith variable not only directly affects that variable but is also transmitted to all of the other endogenous variables through the dynamic structure of the VEC. An impulse response function traces the effect of a one-time shock to one of the innovations on current and future values of the endogenous variables. If the innovations are contemporaneously uncorrelated, then the interpretation of the impulse response is simple--the ith innovation is simply a shock to the ith endogenous variable. However, innovations are usually correlated, and may be viewed as having a common component which cannot be associated with a specific variable. In order to interpret the impulses, it is common to apply a transformation matrix, $\mathrm{B}$, to the innovations so that they become uncorrelated,

$$
\stackrel{\mathrm{V}}{\varepsilon_{t}}=\mathrm{B} \stackrel{\mathrm{V}}{t}_{t} \sim\left(0, \Sigma_{\varepsilon}\right)
$$

where $\Sigma_{\varepsilon}$ is a diagonal covariance matrix. The Cholesky method uses the inverse of the Cholesky factor of the residual covariance matrix in order to orthogonalize the impulses. This method imposes an ordering of the variables and attributes all of the effect of any common component to the variable that comes first in the system. Responses can change if the ordering of the variables change. We impose the following order on the six macro-variables,
Federal non-defense investment spending $\rightarrow$ money supply $\rightarrow$ interest rates $\rightarrow$ private spending (investment and consumption) $\rightarrow$ GDP $\rightarrow$ prices $\rightarrow$ personal taxes $\rightarrow$ unemployment

This particular ordering is reasonable because,

- changes to government spending have historically been followed by increases in the money supply,

- the Treasury has not historically reacted to shocks from the Fed by correcting fiscal policy variables (Stein and Song (2002)),

- prices, personal taxes and the unemployment rate are all lagging indicators of GDP.

It is important to note that the sensitivity of the results to this ordering can be examined by estimating the residual correlation matrix. ${ }^{\mathrm{Xv}}$

As mentioned previously, when cointegration is present but not imposed in estimation, there is both misspecification error and bias in the computation of the impulse response function. The results of the Saikkonen and Lutkepohl (1999) test for cointegration are in Table 1. The null and alternative hypotheses are,

$$
\begin{aligned}
& H_{0}: \text { Cointegration Rank }=r \\
& H_{A}: \text { Cointegration Rank }>r \\
& (r=1,2,3,4,5,6),
\end{aligned}
$$

and the variables are: nominal Federal non-defense investment spending, the real M1 money supply, the nominal long-term Treasury rate, real private net investment spending, real private consumption spending, real GDP, the GDP implicit chained price deflator, real personal current taxes and the unemployment rate.

There is evidence of cointegration amongst the variables and the order of cointegration is three. Hence, there are three linear combinations of the variables that are stationary and three error correction terms that appear in each equation. In addition to the cointegration test results, on the bottom of Table 1 are the results of the lag length test. According to all of the criteria, the selected lag period is two (2). The coefficient estimates of the VEC, loading coefficients, and the corresponding cointegrating equation are in Tables 2,3 , and 4 , respectively. ${ }^{\text {xvi }}$ 
Am. J. Soc. Mgmt. Sci., 2010, 1(1): 24-38

Table 1: Cointegration Test Results Saikkonen and Lutkepohl Test

Sample Range: [1959 Q3, 2008 Q4], T = 198

Included Lags (levels): 2

Dimension of the Process: 9

Intercept Included

Response Surface Computed:

\begin{tabular}{lrrrrrr} 
& LR & Pval & 90\% & 95\% & 99\% & \\
\\
\hdashline 0 & 305.12 & 0.0000 & 173.15 & 179.32 & \\
1 & 189.38 & 0.0000 & 137.94 & 143.49 & 191.29 & \\
2 & 119.31 & 0.0143 & & 106.73 & 111.65 & 121.28 \\
3 & 73.31 & 0.2315 & 79.51 & 83.80 & 92.26 \\
4 & 48.16 & 0.3381 & 56.28 & 59.95 & 67.24 \\
5 & 28.67 & 0.4333 & 37.04 & 40.07 & 46.20 \\
6 & 13.38 & 0.5964 & 21.76 & 24.16 & 29.11 \\
7 & 5.76 & 0.4713 & 10.47 & 12.26 & 16.10 \\
8 & 1.35 & 0.2841 & 2.98 & 4.13 & 6.93
\end{tabular}

Optimal Endogenous Lags from Information Criteria

Sample Range: [1961 Q3, 2008 Q4], T = 190

Optimal Number of Lags (searched up to 10 lags of levels):

Akaike Info Criterion: 2

Final Prediction Error: 2

Hannan-Quinn Criterion:

Schwarz Criterion: 2 


\section{Table 2: VEC Estimates}

Endogenous Lags (diffs): 2

Sample Range: [1959 Q 4, 2008 Q 4], T=197

Estimation Procedure:

Johansen

\section{Lagged endogenous term:}

d(LOG REAL $P$

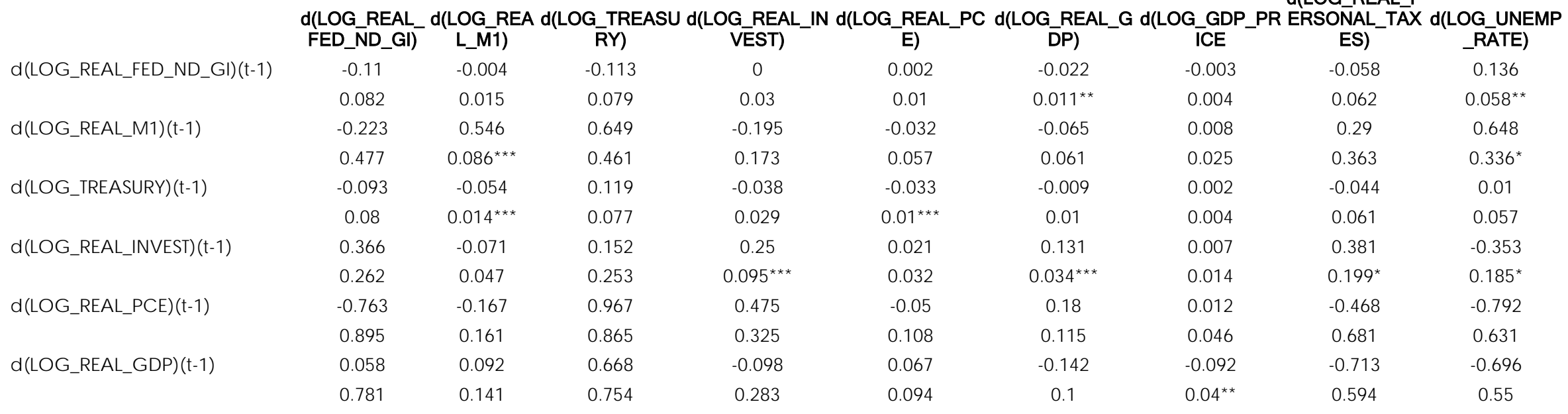




\section{Table 2: VEC Estimates (Continued)}

$\mathbf{m}$

d(LOG_REAL_FED_ND_GI) d(LOG_REAL_M1) d(LOG_TREASURY) d(LOG_REAL_INVEST) d(LOG_REAL_PCE) d(LOG_REAL_GDP) d(LOG_GDP_PRICE d(LOG_REAL_PERSONAL_TAXES) d(LOG_UNEMP_RATE)

\begin{tabular}{|c|c|c|c|c|c|c|c|c|c|}
\hline d(LOG_GDP_PRICE)(t-1) & 2.218 & 0.13 & 2.497 & 0.333 & -0.391 & 0.082 & 0.533 & 0.331 & 1.561 \\
\hline & 1.493 & 0.269 & $1.443 *$ & 0.542 & $0.18^{* *}$ & 0.191 & $0.077^{* * *}$ & 1.135 & 1.052 \\
\hline \multirow{2}{*}{$\begin{array}{l}\mathrm{d}(\text { LOG_REAL_PERSO NAL_TAXES) } \\
(\mathrm{t}-1)\end{array}$} & 0.029 & 0.004 & -0.026 & 0.021 & -0.007 & 0.001 & -0.009 & -0.411 & -0.074 \\
\hline & -0.1 & 0.018 & 0.097 & 0.036 & 0.012 & 0.013 & $0.005^{*}$ & $0.076^{* 1 * k}$ & 0.071 \\
\hline \multirow[t]{2}{*}{ d(LOG_UNEMP_RATE)(t-1) } & 0.096 & 0.017 & 0.087 & -0.074 & -0.018 & -0.012 & -0.024 & -0.366 & 0.295 \\
\hline & 0.12 & 0.022 & 0.116 & $0.044^{*}$ & 0.014 & -0.015 & $0.006^{* * *}$ & $0.091^{* * *}$ & $0.085^{\text {*ak }}$ \\
\hline \multirow[t]{2}{*}{ d(LOG_REAL_FED_ND_GI)(t-2) } & 0.026 & 0.01 & -0.1 & 0.015 & -0.002 & -0.014 & 0.001 & 0.004 & 0.136 \\
\hline & -0.08 & 0.014 & -0.077 & -0.029 & -0.01 & 0.01 & 0.004 & 0.061 & $0.056^{* *}$ \\
\hline \multirow[t]{2}{*}{$\mathrm{d}($ LOG_REAL_M1)(t-2) } & 0.222 & 0.126 & 0.251 & 0.142 & 0.019 & 0.046 & 0.005 & -0.363 & -0.481 \\
\hline & -0.471 & 0.085 & -0.455 & -0.171 & -0.057 & -0.06 & -0.024 & 0.358 & 0.332 \\
\hline \multirow[t]{2}{*}{$\mathrm{d}($ LOG_TREASURY)(t-2) } & 0.121 & -0.006 & -0.083 & -0.07 & -0.016 & -0.007 & 0.001 & 0.041 & 0.045 \\
\hline & -0.085 & 0.015 & 0.082 & $0.031^{* * *}$ & 0.01 & 0.011 & 0.004 & 0.065 & 0.06 \\
\hline \multirow[t]{2}{*}{ d(LOG_REAL_INVEST)(t-2) } & -0.162 & 0.04 & 0.244 & 0.198 & 0.042 & 0.097 & 0.001 & -0.064 & -0.044 \\
\hline & 0.27 & 0.049 & 0.261 & $.1^{* *}$ & 0.032 & $0.035^{* * *}$ & 0.014 & 0.205 & 0.19 \\
\hline \multirow[t]{2}{*}{$d($ LOG_REAL_PCE)(t-2) } & 1.614 & -0.003 & -1.341 & 0.119 & 0.023 & 0.077 & -0.07 & 1.118 & 1.1 \\
\hline & $0.836 *$ & 0.151 & $0.808 *$ & 0.303 & 0.101 & 0.107 & 0.043 & $0.636 *$ & $0.589 *$ \\
\hline
\end{tabular}

\section{Lagged endogenous term:}

d(LOG_REAL_FED_ND_GI) d(LOG_REAL_M1) d(LOG_TREASURY) d(LOG_REAL_INVEST) d(LOG_REAL_PCE) d(LOG_REAL_GDP) d(LOG_GDP_PRICE d(LOG_REAL_PERSONAL_TAXES) d(LOG_UNEMP_RATE)

$\begin{array}{lccc}\text { d(LOG_REAL_GDP)(t-2) } & 0.265 & 0.023 & 0.335 \\ & 0.724 & 0.13 & 0.699 \\ \text { d(LOG_GDP_PRICE)(t-2) } & -2.795 & -0.593 & 3.027 \\ & 1.541^{*} & 0.278^{* *} & 1.48 \\ \text { d(LOG_REAL_PERSO NAL_TAXES) } & & 0.002 & 0.011 \\ \text { (t-2) } & 0.073 & 0.018 & 0.096 \\ & 0.099 & 0.027 & -0.048 \\ \text {-0.083 } & 0.055 & 0.022 & 0.116 \\ \text { * - Sta tistic a lly Signific ant at .10 Level } & & \\ \text { ** - Statistic a lly Signific a nt at .05 Level } & & \\ \text { *** - Sta tistic a lly Signific ant at .01 Level } & \end{array}$

$-1.504$

699

$0.087 \quad 0.093$

$-0.043$

0.55

0.51

3.027

$-0.503$

0.04

$-0.041$

0.249

$-0.173$

$-0.199$

$\begin{array}{llll}0.559 & 0.185 & 0.197 & 0.08^{* * *}\end{array}$

1.172

1.086

$\begin{array}{llll}0.055 & 0.015 & 0.021 & -0.011\end{array}$

$-0.075$

$-0.111$

$0.036 \quad 0.012$

0.013

$0.005^{* *}$

0.075

0.07

0.048

0.057

0.022

0.051

$-0.006$

$-0.114$

0.091

0.084

*** - Sta tistic a lly Signific a nt at .01 Level 
Table 3: Loading Coefficients

\begin{tabular}{|c|c|c|c|c|c|c|c|c|c|}
\hline & $\begin{array}{l}\text { d(LOG_REAL } \\
\text { D_ND_GI) }\end{array}$ & $\begin{array}{c}\text { (LOG_RE } \\
\text { L_M1) }\end{array}$ & $\begin{array}{l}\text { (LOG_TRE } \\
\text { SURY) }\end{array}$ & $\begin{array}{c}\text { LOG_REA } \\
\text { NVEST) }\end{array}$ & $\begin{array}{c}\text { d(LOG_REA } \\
\text { L_PCE) }\end{array}$ & $\begin{array}{c}\text { (LOG_REA } \\
\text { _GDP) }\end{array}$ & $\begin{array}{l}\text { LOG_GDP } \\
\text { PRICE }\end{array}$ & $\begin{array}{c}\text { G_REAL_PER } \\
\text { AL_TAXES) }\end{array}$ & $\begin{array}{l}\text { OG_UNEMF } \\
\text { _RATE) }\end{array}$ \\
\hline \multirow[t]{2}{*}{ ec $1(t-1)$} & 0.045 & 0.001 & 0.032 & 0.004 & 0.008 & 0.03 & -0.002 & -0.007 & -0.065 \\
\hline & 0.035 & 0.006 & 0.034 & 0.013 & $0.004^{* *}$ & $0.005^{* 1 *}$ & 0.002 & 0.027 & $0.025^{* 1 *}$ \\
\hline \multirow[t]{2}{*}{ ec $2(t-1)$} & 0.02 & 0 & 0.018 & 0.003 & -0.002 & 0.007 & -0.003 & -0.015 & -0.04 \\
\hline & 0.014 & 0.002 & 0.013 & 0.005 & 0.002 & $0.002^{* k *}$ & $0.001^{* 1 * k}$ & 0.01 & $0.01^{* 1 *}$ \\
\hline \multirow[t]{2}{*}{ ec $3(t-1)$} & 0.007 & 0.006 & -0.055 & 0.013 & 0.008 & 0.007 & 0.002 & 0.003 & -0.02 \\
\hline & 0.016 & $0.003^{* *}$ & $0.016^{* * k}$ & $0.006^{* *}$ & $0.002^{* 1 k}$ & $0.002^{* * 1 *}$ & $0.001^{* *}$ & 0.012 & $0.012^{*}$ \\
\hline
\end{tabular}

Table 4: Cointegration Equation

Estimated Cointegration Relations

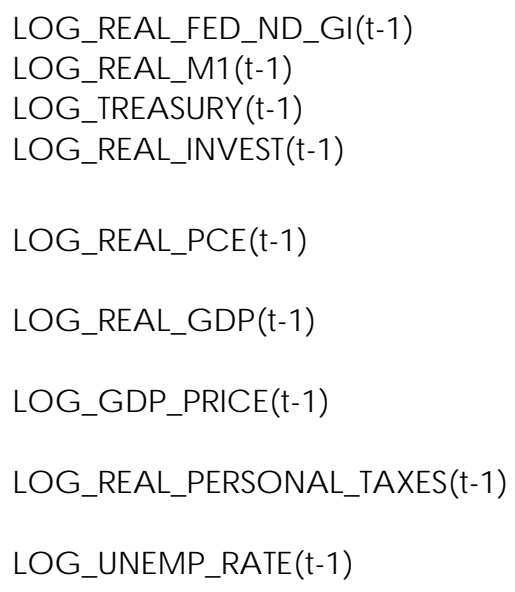

Intercept

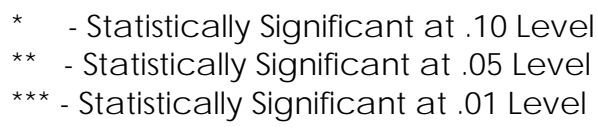

$\begin{array}{cc}\text { ec 2(t-1) } & \text { ec 3(t-1) } \\ 0 & 0 \\ 1 & 0 \\ 0 & 1 \\ -0.084 & -0.3 \\ 0.984 & 0.67 \\ -1.194 & -2.966 \\ 5.287 & 3.597 \\ 2.719 & 8.056 \\ 6.271 & 4.266^{* *} \\ -0.263 & -3.614 \\ 0.82 & 0.558^{* * *} \\ -0.949 & -0.114 \\ 0.817 & 0.556 \\ 1.828 & 2.143 \\ 0.562^{* * *} & 0.382^{* * *} \\ -18.498 & -50.416 \\ 14.319 & 9.741^{* * *}\end{array}$




\section{Table 5: Impulse Responses}

\section{$1^{\text {st }}$ Quarter 2009 - $4^{\text {th }}$ Quarter 2010}

\section{Impulse: LOG_REAL_NONDEF_GI}

\begin{tabular}{|c|c|c|c|c|c|c|c|c|}
\hline Peniod & LOG_REAL_M1 & LOG_TREASURY & LOG_REAL_INVEST & LOG_REAL_PCE & LOG_REAL_GDP & \multicolumn{3}{|c|}{ LOG_GDP_PRICE LOG_REAL_PERSONAL_TAXES LOG_UNEMP_RATE } \\
\hline $\begin{array}{l}0 \text { Point Estimate } \\
95 \% \mathrm{Cl}\end{array}$ & {$\left[\begin{array}{c}0.0009^{* *} \\
{[0.0001,0.0015]}\end{array}\right.$} & $\begin{array}{c}0.0083^{* *} \\
{[0.0040,0.0115]}\end{array}$ & $\begin{array}{c}0.0004 \\
{[-0.0010,0.0017]}\end{array}$ & {$\left[\begin{array}{c}-0.0004 \\
-0.0008,0.0000]\end{array}\right.$} & $\begin{array}{c}0.0005 \\
{[-0.0000,0.0010]}\end{array}$ & $\begin{array}{c}-0.0001 \\
{[-0.0003,0.0001]}\end{array}$ & $\begin{array}{c}0.0032^{* *} \\
{[0.0004,0.0056]}\end{array}$ & $\begin{array}{c}-0.0001 \\
{[-0.0028,0.0025]}\end{array}$ \\
\hline $\begin{array}{l}1 \text { Point Estimate } \\
95 \% \mathrm{Cl}\end{array}$ & $\begin{array}{c}0.0009 \\
{[-0.0006,0.0022]}\end{array}$ & $\begin{array}{c}0.0043^{* *} \\
{[-0.0018,0.0091]}\end{array}$ & $\begin{array}{c}0.0002 \\
{[-0.0020,0.0024]}\end{array}$ & {$\left[\begin{array}{c}-0.0002 \\
{[-0.0008,0.0006]}\end{array}\right.$} & $\begin{array}{c}0.0003 \\
{[-0.0005,0.0011]}\end{array}$ & $\begin{array}{c}-0.0004 \\
{[-0.0007,0.0000]}\end{array}$ & $\begin{array}{c}-0.0012 \\
{[-0.0048,0.0020]}\end{array}$ & $\begin{array}{c}0.0041 \\
{[-0.0011,0.0085]}\end{array}$ \\
\hline $\begin{array}{l}2 \text { Point Estimate } \\
95 \% \mathrm{Cl}\end{array}$ & $\begin{array}{c}0.0019 \\
{[-0.0003,0.0039]}\end{array}$ & $\begin{array}{l}-0.0002 \\
{[-0.0077,0.0064]}\end{array}$ & $\begin{array}{c}0.0009 \\
{[-0.0022,0.0040]}\end{array}$ & $\begin{array}{c}0.0002 \\
{[-0.0006,0.0011]}\end{array}$ & $\begin{array}{c}0.0009 \\
{[-0.0002,0.0019]}\end{array}$ & $\begin{array}{c}-0.0006 \\
{[-0.0011,-0.0000]}\end{array}$ & $\begin{array}{c}-0.0019 \\
{[-0.0058,0.0025]}\end{array}$ & $\begin{array}{c}0.0069 \\
{[-0.0005,0.0127]}\end{array}$ \\
\hline $\begin{array}{l}3 \text { Point Estimate } \\
95 \% \mathrm{Cl}\end{array}$ & {$\left[\begin{array}{c}0.0030^{* *} \\
{[0.0000,0.0056]}\end{array}\right.$} & $\begin{array}{l}-0.0005 \\
{[-0.0078,0.0064]}\end{array}$ & $\begin{array}{c}0.0018 \\
{[-0.0019,0.0055]}\end{array}$ & $\begin{array}{c}0.0008 \\
{[-0.0001,0.0018]}\end{array}$ & $\begin{array}{c}0.0020^{* *} \\
{[0.0008,0.0031]}\end{array}$ & $\begin{array}{c}-0.0009^{* *} \\
{[-0.0015,-0.0001]}\end{array}$ & $\begin{array}{c}-0.0026 \\
{[-0.0061,0.0023]}\end{array}$ & $\begin{array}{c}-0.0045 \\
{[-0.0049,0.0111]}\end{array}$ \\
\hline $\begin{array}{l}4 \text { Point Estimate } \\
95 \% \mathrm{Cl}\end{array}$ & {$\left[\begin{array}{c}0.0040^{* *} \\
0.0004,0.0070]\end{array}\right.$} & $\begin{array}{c}-0.0008 \\
{[-0.0083,0.0072]}\end{array}$ & $\begin{array}{c}0.0035 \\
{[-0.0008,0.0076]}\end{array}$ & {$\left[\begin{array}{c}0.0015^{* *} \\
{[0.0003,0.0026]}\end{array}\right.$} & $\begin{array}{c}0.0029 * * \\
{[0.0015,0.0041]}\end{array}$ & $\begin{array}{c}-0.0013^{\text {** }} \\
{[-0.0020,-0.0003]}\end{array}$ & $\begin{array}{c}-0.0033 \\
{[-0.0072,0.0023]}\end{array}$ & $\begin{array}{c}-0.0004 \\
{[-0.0110,0.0071]}\end{array}$ \\
\hline $\begin{array}{l}5 \text { Point Estimate } \\
95 \% \mathrm{Cl}\end{array}$ & {$\left[\begin{array}{c}0.0048^{* *} \\
{[0.0006,0.0080]}\end{array}\right.$} & $\begin{array}{l}-0.0017 \\
{[-0.0095,0.0070]}\end{array}$ & $\begin{array}{c}0.0051^{* *} \\
{[0.0002,0.0094]}\end{array}$ & $\begin{array}{c}0.0021^{* *} \\
{[0.0006,0.0032]}\end{array}$ & $\begin{array}{c}0.0037^{* *} \\
{[0.0019,0.0050]}\end{array}$ & $\begin{array}{c}-0.0015^{* *} \\
{[-0.0024,-0.0003]}\end{array}$ & $\begin{array}{c}-0.0020 \\
{[-0.0064,0.0039]}\end{array}$ & $\begin{array}{c}-0.0058 \\
{[-0.0173,0.0026]}\end{array}$ \\
\hline $\begin{array}{l}6 \text { Point Estimate } \\
95 \% \mathrm{Cl}\end{array}$ & {$\left[\begin{array}{c}0.0054^{* *} \\
{[0.0007,0.0089]}\end{array}\right.$} & $\begin{array}{c}-0.0024 \\
{[-0.0103,0.0071]}\end{array}$ & $\begin{array}{c}0.0066^{* *} \\
{[0.0013,0.0111]}\end{array}$ & $\begin{array}{c}0.0026^{* *} \\
{[0.0008,0.0038]}\end{array}$ & $\begin{array}{c}0.0044^{* *} \\
{[0.0024,0.0057]}\end{array}$ & $\begin{array}{c}-0.0018^{* *} \\
{[-0.0028,-0.0004]}\end{array}$ & $\begin{array}{c}-0.0006 \\
{[-0.0050,0.0055]}\end{array}$ & $\begin{array}{c}-0.0107 * * \\
{[-0.0225,-0.0005]}\end{array}$ \\
\hline $\begin{array}{l}7 \text { Point Estimate } \\
95 \% \mathrm{Cl}\end{array}$ & {$\left[\begin{array}{c}0.0059^{* *} \\
{[0.0007,0.0095]}\end{array}\right.$} & $\begin{array}{l}-0.0025 \\
{[-0.0102,0.0078]}\end{array}$ & 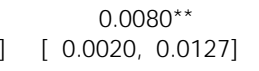 & $\begin{array}{c}0.0031^{* *} \\
{[0.0010,0.0043]}\end{array}$ & $\begin{array}{c}0.0051^{* *} \\
{[0.0028,0.0064]}\end{array}$ & $\begin{array}{c}-0.0019^{* *} \\
{[-0.0030,-0.0004]}\end{array}$ & $\begin{array}{c}0.0006 \\
{[-0.0041,0.0069]}\end{array}$ & $\begin{array}{c}-0.0150^{* *} \\
{[-0.0260,-0.0033]}\end{array}$ \\
\hline $\begin{array}{l}8 \text { Point Estimate } \\
95 \% \mathrm{Cl}\end{array}$ & {$\left[\begin{array}{c}0.0061^{* *} \\
{[0.0006,0.0099]}\end{array}\right.$} & $\begin{array}{c}-0.0022 \\
{[-0.0096,0.0085]}\end{array}$ & 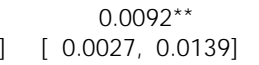 & $\begin{array}{c}0.0035 * * \\
{[0.0012,0.0047]}\end{array}$ & $\begin{array}{c}0.0057^{* *} \\
{[0.0031,0.0070]}\end{array}$ & $\begin{array}{c}-0.0021^{* *} \\
{[-0.0033,-0.0003]}\end{array}$ & $\begin{array}{c}0.0017 \\
{[-0.0034,0.0079]}\end{array}$ & $\begin{array}{c}-0.0188^{* *} \\
{[-0.0294,-0.0056]}\end{array}$ \\
\hline
\end{tabular}

** - Statistic a lly Signific ant at .05 Level 
Am. J. Soc. Mgmt. Sci., 2010, 1(1): 24-38

Table 6: Federal Non-Defense Investment Multiplier $1^{\text {st }}$ Quarter $2009-4^{\text {th }}$ Quarter 2010

\begin{tabular}{|c|c|c|}
\hline Period & Impulse Response & Interim Multiplier \\
\hline 0 Point Estimate & 0.0005 & 0.0656 \\
\hline $95 \% \mathrm{Cl}$ & {$[-0.0005,0.0015]$} & \\
\hline 1 Point Estimate & 0.0003 & 0.0394 \\
\hline $95 \% \mathrm{Cl}$ & {$[-0.0012,0.0016]$} & \\
\hline 2 Point Estimate & 0.0009 & 0.1181 \\
\hline $95 \% \mathrm{Cl}$ & {$[-0.0010,0.0027]$} & \\
\hline 3 Point Estimate & 0.002 & 0.2625 \\
\hline $95 \% \mathrm{Cl}$ & {$\left[\begin{array}{ll}-0.0002, & 0.0042]\end{array}\right.$} & \\
\hline 4 Point Estimate & 0.0029 & $0.3806^{* *}$ \\
\hline $95 \% \mathrm{Cl}$ & {$[0.0002,0.0053]$} & \\
\hline 5 Point Estimate & 0.0037 & $0.4856^{* *}$ \\
\hline $95 \% \mathrm{Cl}$ & {$[0.0005,0.0063]$} & \\
\hline 6 Point Estimate & 0.0044 & $0.5774^{* *}$ \\
\hline $95 \% \mathrm{Cl}$ & {$[0.0007,0.0071]$} & \\
\hline 7 Point Estimate & 0.0051 & $0.6693^{* *}$ \\
\hline $95 \% \mathrm{Cl}$ & {$[0.0008,0.0080]$} & \\
\hline 8 Point Estimate & 0.0057 & $0.7480^{* *}$ \\
\hline $95 \% \mathrm{Cl}$ & {$[0.0010,0.0088]$} & \\
\hline
\end{tabular}

The VEC impulse response function and the 95 percent confidence bounds for each of the eight response variables may be found in Table 5 . The confidence bounds were generated by bootstrapping and using Hall's Percentile Interval (Hall (1972)). xvii It is interesting to note that a one standard deviation increase in Federal non-defense investment spending at the end of 2008 would increase the real M1 money supply beginning in the $3^{\text {rd }}$ Quarter 2009, real net investment spending by businesses beginning in the $1^{\text {st }}$ Quarter 2010, real personal consumption beginning in the $4^{\text {th }}$ Quarter 2009, and real gross domestic product beginning in the $3^{\text {rd }}$ Quarter 2009. ${ }^{\text {xviii }}$ The unemployment rate decreases in response to a one standard deviation increase in Federal infrastructure spending beginning in the $2^{\text {nd }}$ Quarter 2010. ${ }^{\text {xix }}$

The interim and accumulated multipliers and the 95 percent bootstrapped confidence intervals for real GDP are in Table 6. The accumulated effects are the summation of the impulse response function up to each period and represent the multiplier after $l$ periods. It is important to note that the values in the Impulse Response and Accumulated Impulse Response columns are measured in percent after multiplication by 100 since the dependent variable is the natural log of real gross domestic product. ${ }^{\mathrm{xx}}$ In order to covert this to a standard interpretation of a multiplier, which would be the change in real gross national product for a unit change in government spending, we follow Ramey (2008) and divide the elasticity coefficient by the average ratio of Federal non-defense investment spending to net domestic product. ${ }^{\mathrm{xxi}}$ For example, the impulse response value in the $4^{\text {th }}$ Quarter 2010 is .57 percent (Table 6). Since the average ratio of Federal non-defense investment spending to net domestic product over the entire period of this study $(1960-2008)$ was .762 percent, this yields an interim multiplier in the $4^{\text {th }}$ Quarter 2010 of approximately 75 cents (.57/.762). A summary of the accumulated multiplier computation from Table 6 is as follows,

- Impact Multiplier: $\quad .0656$ (not statistically significant)

- After One Year: $\quad .8661$

- After Two Years: 3.3333

By the end of the first year, every additional dollar spent on infrastructure generates only about 87 cents in additional income. But after two years, every additional dollar adds $\$ 3.33$ to national income. Thus, $\$ 100 \mathrm{~B}$ of additional spending on infrastructure should increase economic activity by $\$ 333 \mathrm{~B}$ at the end of two years, with a lower bound of $\$ 222 \mathrm{~B}$ and an upper bound of $\$ 496 \mathrm{~B}$.

Barro (2009) estimates the simple defense spending multiplier from 1943 to 1944 to be .8 and concludes that the multiplier is not greater than one when 
combining the data for all wars. Given the bootstrapped confidence intervals in Table 6, the null hypothesis that the Federal non-defense investment accumulated multiplier is equal to one (1) versus the alternative that it is not equal to one (1) can be tested by merely observing whether or not one (1) falls within the interval. The accumulated multipliers between the $1^{\text {st }}$ Quarter 2010 and $4^{\text {th }}$ Quarter 2010 are all significantly different from one (1). ${ }^{x \mathrm{ii}}$

\section{CONCLUSION}

In this analysis, we have discussed two measures that have been used by economists to measure changes in macroeconomic policies: the dynamic multiplier and the impulse response function. These two methods are not necessarily mutually exclusive-imposing restrictions on a VAR model will yield identical multipliers by either summing the impulse responses over time or calculating the dynamic multiplier (Stein and Song (2002)). In the absence of these restrictions, economists using VAR representations have employed sums of coefficients rather than impulse responses to determine multipliers. There are certain advantages of calculating multipliers using impulse response functions since the impulse coefficients reflect both the dynamic aspect of multipliers (they are functions of exogenous, policy variables' innovations) and the interactions of the shocks within a system. However, in the presence of $I(1)$ variables, impulse responses and multipliers should be generated from a VAR with parameter estimates calculated from the corresponding VEC model--otherwise there can be substantial biases at both the long and short horizons.

It is prudent to address the four questions that have been raised previously regarding the effect of the stimulus on the U.S. economy,

- Will the rise in the deficit as a result of the stimulus be financed in such a way that will increase the money supply?

According to the impulse responses in Table 5, the increase in Federal spending expands the real money supply (M1). This probably results during financing as government securities are sold to the non-bank public or foreign investors.

- What will be the influence on private spending (both consumption and investment)?

Once again and looking at Table 5, the increase in Federal spending tends to augment both private investment and consumption spending. This result runs counter to the findings of both Ramey (2008) and Barro (2009). Barro (2009) believes that the multipliers are small because additional government spending "crowds-out" private investment, despite the fact that the literature has shown business investment spending responding little to changing interest rates and mostly to changes in economic activity.

- Because of the lag factor, will increasing government spending today generate inflation in the future?

The type of government spending used in this analysis, infrastructure or investment spending, will not generate future increases in the overall price level. Of course, this is not to say that government spending, per se, does not influence prices. It is more likely that other types of spending, e.g., Federal consumption, may encourage future increases in the overall price level. ${ }^{x \times i i}$

- Will personal taxes have to rise in the future in order to pay for the increased spending in the present?

According to Table 5, the impulse responses for real personal taxes are not significantly different from zero for just about the entire future period. Once again, this does not mean that government spending does not increase future taxes. There may be two confounding influences here. First, it appears that this type of Federal spending may be financed predominantly by bond sales, which is a good thing since the spending is on capital goods. Second, the future period in this study is only two years. Taxes may have to increase further in the future in order to pay the interest on the debt created by the spending.

- Does increased government spending reduce unemployment?

From the results of this study, it is clear that after a lag of five quarters, Federal infrastructure spending will decrease the unemployment rate.

- Finally, what will be the ultimate effect on GDP? Will a stimulus deliver insofar as increasing overall economic activity in the U.S.?

The empirical results of this analysis clearly indicate that increasing Federal infrastructure spending will lead to a "multiplied" rise in gross domestic product from 2009 to 2010.

Finally, it should be noted that the multipliers calculated from the impulse responses in Table 6 are larger than other multipliers that have been computed from other methods and in other research. As mentioned previously, studies put the size of the 
government multiplier between .8 and 1.4. Our multipliers increase to slightly greater than three (3) after two years. A number this large could either foster skepticism regarding the use of impulse responses for calculating multipliers or cast doubt on the previous ways multipliers have been determined. Yet, another study has also shown that impulse responses can generate larger multipliers than other methods. Stein and Song (2002) estimate a VAR in first differences for the variables government spending, the M1 money supply, and real GDP (in that order) for the period 1952 Q1 to 1968 Q2 and then create the impulse response function for GDP based upon a one-standard deviation increase in government spending. The table appears as follows, ${ }^{\text {xiv }}$

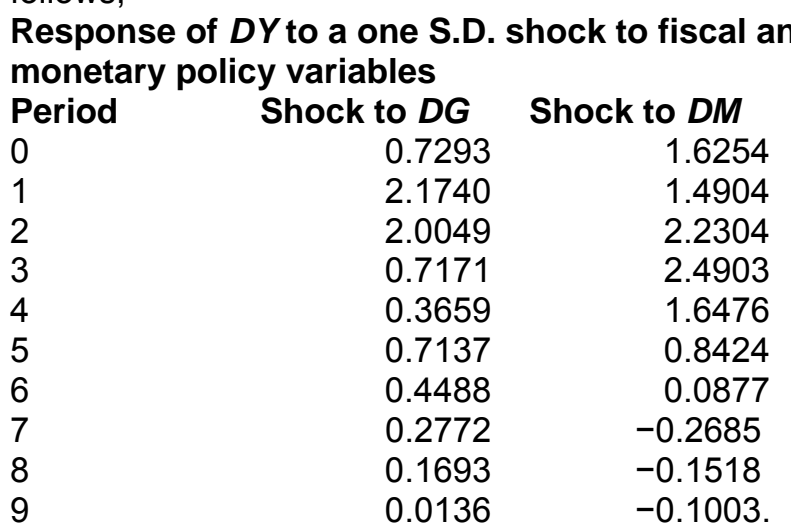

While there are shortcomings to their approach, (e.g., no test for cointegration, lack of statistical properties, etc.), the sum over the nine periods of the "Shock to DG" impulse responses is 7.6138. Thus, the possibility exists that the previous ways of calculating dynamic multipliers, through the use of structural equations or by summing coefficients on dynamic regressions (discussed above), have led to the underestimation of the influence that government spending has had on economies-only additional research will tell.

\section{REFERENCES}

Anderson, L., and Jordan, J., Monetary and Fiscal Actions: A Test of Their Relative Importance in Economic Stabilization. Federal Reserve Bank of St. Louis Review, 99, November 1968, pp. 12-16.

Barro, R.J., Voodoo Multipliers. Economist's Voice, The Berkeley Electronic Press, February 2009.

Benkwitz, A., Lutkepohl, H., Neumann, M., Problems Related to Bootstrapping Impulse Responses of Autoregressive Processes. Econometric Reviews, 19, pp. 69-103.
Blanchard, Olivier and Perotti, Roberto, An Empirical Characterization of the Dynamic Effects of Changes in Government Spending and Taxes on Output. Quarterly Journal of Economics, November 2002, pp. 1329-1368.

Bruggemann, R., Finite Sample Properties of Impulse Response Intervals in SVECMs with Long-Run Identifying Restrictions. Institute of Statistics and Econometrics, Humboldt University, Berlin, Germany, SFB 649, 2006.

Enders, W., Applied Econometric Time Series, Second Edition. New York, NY: John Wiley and Sons, Inc., 2004.

Fisher, D., Monetary and Fiscal Policy. New York, NY: New York University Press, 1988.

Friedman, M., An Economist's Protest. New Jersey: Thomas Horton and Company, 1972.

Hall, P., The Bootstrap and Edgeworth Expansion. New York, NY: Springer Publishers, 1972.

Halvorsen, R. and Palmquist, P., The Interpretation of Dummy Variables in Semilogarithmic Equations. American Economic Review, Vol. 70, 1980, pp. 474475.

Johansen, Soren, Statistical Analysis of Cointegration Vectors, Journal of Economic Dynamics and Control, 12, June-September, 1988, pp. 231-254.

Kennedy, P., Estimation with Correctly Interpreted Dummy Variables in Semilogarithmic Equations. American Economic Review, Vol. 71, 1981, p. 801.

Klein, L., and Young, R., An introduction to econometric forecasting and forecasting models. Lexington, MA: Lexington Books, 1980.

Mitchell, James, The Importance of Long-Run Structure for Impulse Response Analysis in VAR Models. NIESR Discussion Paper \#172, September 2000.

Modigliani, F., Monetary policy and consumption: Linkages via interest rate and wealth effects in the FMP model, Consumer spending and monetary policy: The linkages. Federal Reserve Bank of Boston, 1971, pp. 9-84.

Ramey, V.A., Identifying Government Spending Shocks: It's All in the Timing. National Bureau of Economic Research, June 2008.

Saikkonen, P. and Lutkepohl, H., Local Power of Likelihood Ratio Tests for the Cointegrating Rank of a VAR Process. Econometric Theory, 15, 1999, pp. 15-78.

Sims, C., Macroeconomics and Reality. Econometrica, 48, pp. 1-48.

Stein, S.H., and Song, F.M., Vector Autoregression and the Dynamic Multiplier: A Historical Review. Journal of Policy Modeling, 24, 2002, pp. 283-300. 
Am. J. Soc. Mgmt. Sci., 2010, 1(1): 24-38

Vlaar, P. J. G., On the Asymptotic Distribution of Impulse Response Functions with Long-Run Restrictions, Econometric Theory, 20(5), 2004, pp. 891-903.

\section{ENDNOTES}

' It is assumed that all variables are expressed as mean deviations.

ii Any system with lags greater than one can be rewritten as a system where no lag is greater than one by creating new endogenous variables that are single-period lags.

iiihttp://fairmodel.econ.yale.edu and http://www.macroadvisors.com, respectively.

${ }^{\text {iv }}$ http://www.federalreserve.gov/boarddocs/ speeches/1997/19970105.htm

v Since there were $k$ endogenous and $w$ exogenous variables, in the VAR model, the vector $W_{t}$ is $d=k+w$ by one (1)

vi Of course, the problem with this orthogonalization is that the impulse response results depend upon the ordering of the components of $\stackrel{\mathrm{v}}{W_{t}}$.

vii See Bruggemann (2006), Appendix A, p. 27, for a derivation of the variance-covariance matrix $\Sigma_{\hat{\varphi}}$.

viii See Benkwitz, et. al., 2000, for further information.

ix http://woodwardhall.wordpress.com/2008/12/11/measuring-theeffect-of-infrastructure-spending-on-gdp/.

x http://gregmankiw.blogspot.com/2008/12/spending-and-tax$\underline{\text { multipliers.html }}$

${ }^{\mathrm{xi}}$ http://www.bepress.org/ev.

xii This analysis was also performed for government non-defense consumption, defense consumption, and defense investment expenditures. Results are available upon request from the authors.

xiii JMulti 4.0 is the only software that generates bootstrapped confidence intervals for the impulse response function.

xiv http://www.voanews.com/english/archive/2009-02/2009-02-11voa50.cfm?moddate $=2009-02-11$.

${ }^{x v}$ The residual correlation matrix did not have any correlations that were above .1 in absolute value.

xvi Since the focus of this analysis is on the calculation of the impulse response functions and the government spending multipliers, we will not belabor the explanation of the VEC results. xvii It is determined as $C I=\left[\varphi_{j c}^{i}-t_{\left(1-\frac{\alpha}{2}\right)}, \varphi_{j c}^{i}-t_{\left(\frac{\alpha}{2}\right)}\right]$,

where $t_{\left(\frac{\alpha}{2}\right)}$ and $t_{\left(1-\frac{\alpha}{2}\right)}$ are the $\frac{\alpha}{2}$ and $\left(1-\frac{\alpha}{2}\right)$ quantiles of

the distribution of $\hat{\varphi}_{j c}^{i}-\varphi_{j c}^{i}$.

xviii In Table V, we are referring to the positive impulse responses whose 95 percent confidence intervals do not contain zero (0).

xix In Table $\mathrm{V}$, we are referring to the negative impulse responses whose 95 percent confidence intervals do not contain zero (0).

${ }^{x x}$ When the dependent variable is measured in logs and the explanatory variables are in raw form, (the innovations in equation (8) above), the coefficient is interpreted as a percent after it is multiplied by 100 . See Halvorsen and Palmquist (1980) and Kennedy (1981).

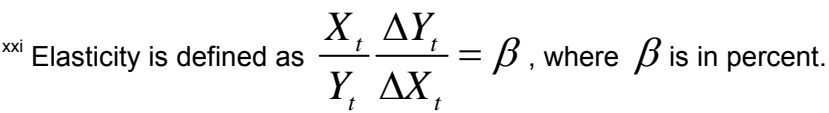

Hence, $\frac{\Delta Y_{t}}{\Delta X_{t}}=\beta \div \frac{X_{t}}{Y_{t}}$ and in the above case, $\frac{X_{t}}{Y_{t}}$ is expressed as a constant and is the average proportion of Federal non-defense investment spending to NDP.

xxii Although not calculated in Table VI, the 95 percent confidence bounds for the multipliers can be determined by first multiplying the lower and upper bounds by 100 and then dividing by .762 .

xxiii We have found that impulses in Federal defense and nondefense consumption spending tend to increase the GDP Implicit Price Deflator over time.

xxiv Stein and Song (2002), page 298. The coefficients were totaled to calculate the multiplier. The authors did not perform the summation in their paper. 